\title{
NATURAL REFORESTATION OF ABANDONED EUCALYPT PLANTATIONS IN THE BRASILIA NATIONAL FOREST
}

\author{
Charles E. Knadler, Jr. \\ 1438 Box Elder Drive \\ Alpine, UT 84004, USA
}

\author{
Georgia Sinimbu \\ Department of Biology \\ The University of Utah \\ Salt Lake City, UT 84112, USA
}

\begin{abstract}
Using data from a census of trees in both native Cerrado and eucalypt plantation areas in the Brasilia National Forest, a discrete event simulation was developed and used to predict the results of fifty-years of natural reforestation. The model predicts long-term equilibrium between eucalypt and native Cerrado species with the eucalypt population dominating. Field observations suggest that eucalypt species are not a threat to the adjacent undisturbed Cerrado areas. It is hypothesized that the native grasses inhibit the successful dispersal and germination of the Eucalyptus' anemochoric (air-borne) seeds in the Cerrado habitat.
\end{abstract}

\section{INTRODUCTION}

\subsection{Eucalyptus Plantations}

Renewable resources are potential solutions for several critical human needs. Eucalypt plantations have been viewed as an attractive alternative to harvesting old growth forests and Cerrado for charcoal, paper or wood production. Eucalypt species are fast growing and several have relatively few pests in the Brazilian Cerrado. Eucalyptus dominates, as a worldwide monoculture hardwood, planted in 10-15 million ha. (Neilson 2000). In Brazil, it is the basis of highly productive managed forests yielding 9-39 Mg of biomass per ha. (Stape 2002). However there is considerable debate as to whether the environmental costs of monoculture cultivation exceed the benefits (Couto and Betters 1995).

\subsection{Brazilian Eucalypt Plantations}

Savanna, primarily in the Brazilian Cerrado biome (Figure 1), is the preferred environment for eucalypt plantations as a result of three characteristics: 1) it has extensive area with favorable climate for agriculture; 2) its trees are small and easily removed; and 3) its vegetation consists of twisted trees and shrubs which have little apparent economic value, other than their use for charcoal. These factors have resulted in large scale destruction of the Cerrado habitat and the biome being classified as a "Hotspot of biodiversity" (Myers et al. 2000). Hotspots of biodiversity are areas featuring exceptional concentrations of endemic species and experiencing exceptional loss of habitat (Myers 1988). For instance Minas Gerais, a largely savanna dominated state, has 1,535,750 ha. of eucalypt plantations (Alternativas 2001).

Eucalypts have been planted in Brazil for over a century, but it wasn't until the 1960's that large expansion of commercial plantations started as a result of Brazilian government financial incentives (Couto and Betters 1995). Although some of these plantations are still profitable, many others were abandoned in the 1990's due to discontinuation of the incentives. 


\section{Knadler and Sinimbu}

Today, it is a priority for some to eliminate eucalypt plantations and restore the original area (Lang 2011). It is debatable whether or not it would be economically feasible to truly restore the large savannas that have been cleared for commercial cultivation of biomass. Natural reforestation is often the result of neglect rather than active restoration projects. In periods of economic distress, it is reasonable to assume at least some abandoned plantations will not be subject of active restoration projects.

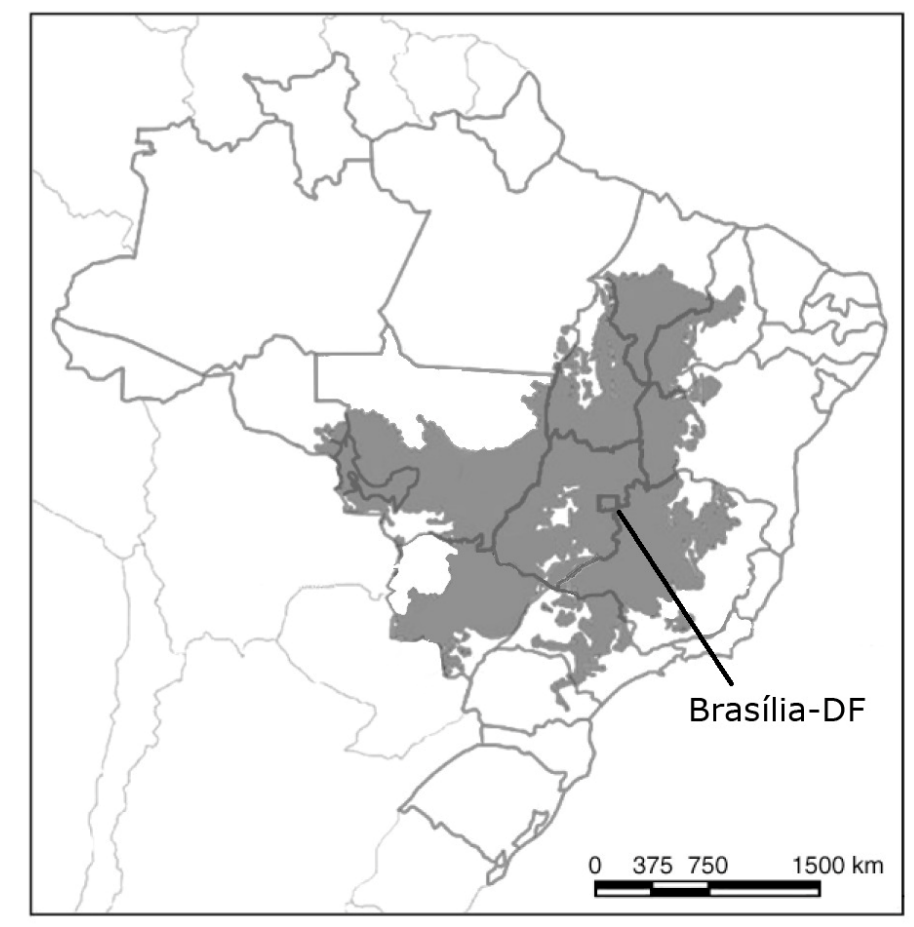

Figure 1: Map of Brazil with the territorial distribution of Cerrado biome (gray area) and the study site region, Brasilia-DF.

\subsection{Plant census}

A tree census was conducted from October to December 2006 in the Brasilia National Forest, Distrito Federal, Brazil (Sinimbu 2006). All trees in 14 plots in four different eucalypt planting groups (approximately 32 hectares each) and in 9 plots of neighboring Cerrado areas were counted. The eucalypt planting groups consisted of plots of two Eucalyptus species: E. saligna and E. urophylla.

Plots $\left(20 \times 50 \mathrm{~m}^{2}\right)$ were chosen at different distances from the road that separated the Cerrado from the plantations. The census included number of trees, their species and their diameter $30 \mathrm{~cm}$ above ground level (D30) of all specimens meeting a criterion of at least 3 centimeters D30 (Sinimbu 2006).

All observed species propagate by seed and their dispersal mechanisms were identified as: 1) amenochory (i.e. seeds dispersed by the wind), 2) barochory (i.e. seeds dispersed by gravity), 3) zoochory (i.e. seeds dispersed by animals), or 4) unknown. Most of the observed eucalypts sprouted from the last harvest's stumps. When these trees matured, they also dispersed seeds.

\section{APPROACH}

\subsection{Model Cycle}

A modified Law and Kelton (1991) model cycle was used for the Cerrado model. They identify the following steps for constructing valid models: 


\section{Knadler and Sinimbu}

1. Observe and analyze the system;

2. Develop the conceptual model;

3. Validate the conceptual model;

4. Program the model;

5. Verify the correctness of the program;

6. Make model runs;

7. Validate the model runs; and

8. Project the model to other time intervals (adapted from Lazowska et al 1984).

\subsubsection{Observe and Analyze the System}

For every tree, on the 23 plots, with a D30 (diameter $30 \mathrm{~cm}$ above ground level) greater than or equal to 3 $\mathrm{cm}$., the tree census identifies its species, diameter and seed dispersal mechanism. These data were used to determine the effectiveness of the different seed dispersal mechanisms as a function of distance from the native Cerrado plots. It was found that distance did not have a statistically significant impact on this distribution.

However, the plots of the two eucalypt species had different observed distributions for both the native Cerrado species and the eucalypt species. The means, maximums and minimums were determined for each species' plots (Table 1).

E. urophylla trees produce seeds at less than two years of age (World Agroforestry Centre 2011b) while E. saligna trees do not produce seeds until they are about 7-8 years old (World Agroforestry Centre 2011a). For each of the two species, all the eucalypt trees in that species' census were ordered by diameter and estimates were made of made of which trees were generated from stumps and which were the results of the seeds from this initial and subsequent tree growth.

Table 1: Number of trees observed per abandoned eucalypt plantation plot

\begin{tabular}{|c|c|c|c|c|c|c|}
\hline & \multicolumn{3}{|c|}{ Native Cerrado Species } & \multicolumn{3}{c|}{ Eucalypts } \\
\hline & Minimum & Mean & Maximum & Minimum & Mean & Maximum \\
\hline E. saligna plots & 18 & 42 & 74 & 35 & 49 & 71 \\
\hline E.urophylla plots & 6 & 52 & 143 & 45 & 71 & 90 \\
\hline
\end{tabular}

\subsubsection{Conceptual Model}

The purpose of this simulation was to develop a model to predict the degree to which the recolonization of abandoned eucalypt plantations will occur as a result of natural native species seed dispersal. The conceptual model consisted of E. saligna and E. urophylla $20 \mathrm{~m}$ by $50 \mathrm{~m}$ plots and neighboring Cerrado. The model assumes that the eucalypt plots were harvested and then neglected. The model consists of plots, six events (Table 2), ninety-eight native Cerrado species and two eucalypt species.

\subsubsection{Habitat}

Plots were modeled as $10 \times 25$ grids of $2 \times 2 \mathrm{~m}^{2}$ areas. A single simulation run consists of the events impacting each member of the set of 250 grid positions for each of a user specified number of plots for each year since the last eucalypt harvest. The eucalypt stumps are assumed to be randomly distributed over the plot. 


\section{Knadler and Sinimbu}

\subsubsection{Propagation}

In the simulation, trees are assumed to propagate in two ways either from the residual eucalypt stumps or else from seeds. The three seed dispersal mechanisms are characterized by their probability of successfully dispersing to a grid position. These probabilities are estimated using the analysis of the census data (number of trees sixteen years post last harvest). It is assumed that if any herbicides had been formerly applied to the eucalypt plots, they do not inhibit seed dispersal in the years post harvest. Eucalypt seeds are assumed not to be present until the plot's species has reached sexual maturity, and trees generate such large number of seeds, that the dispersal probabilities are not varied after the initial growth reaches maturity. It is assumed that the conditions existing on the plot, rather than the additional tree population determine the success of additional eucalypts generating from seeds. The number of eucalypts which regenerate from the stumps is a random process based on the parameters determined from the estimates of eucalypt tree age discussed above.

Two of the 65 (the model includes 35 additional Cerrado species) observed tree species had unknown seed dispersal mechanisms (representing 25 of the total 2286 trees counted). The probability distribution of observed trees' dispersal mechanisms was anemochoric 0.333 , zoochoric 0.333 , barochoric 0.286 , and unknown 0.048 .

Table 2: Simulation Events

\begin{tabular}{|l|l|}
\hline \multicolumn{1}{|c|}{ Event Name } & \multicolumn{1}{c|}{ Event Definition } \\
\hline seed dispersal & Determines if a seed disperses for each grid position. \\
\hline seed germination & Determines if a seed germinates or not \\
\hline seedling survival & Determines if a seedling survives or not \\
\hline plot observation & $\begin{array}{l}\text { At the end of each plot's simulation run, generates the census of trees } \\
\text { meeting the D30 } 3 \mathrm{~cm} \text {. diameter criterion and generates detailed simulation } \\
\text { results. }\end{array}$ \\
\hline E. urophylla maturation & $\begin{array}{l}\text { An E. urophylla tree becomes sexually mature and disperses seeds this and } \\
\text { each succeeding year. }\end{array}$ \\
\hline E. saligna maturation & $\begin{array}{l}\text { An E. saligna tree becomes sexually mature and disperses seeds this and } \\
\text { each succeeding year. }\end{array}$ \\
\hline Interval data generation & $\begin{array}{l}\text { At the end of each five-year interval, this event determines which trees } \\
\text { meet the D30 } 3 \mathrm{~cm} \text {. criterion and generates the tree census. }\end{array}$ \\
\hline
\end{tabular}

\subsubsection{Trees}

The tree life cycle is modeled by four states: seed, seedling, stumps (eucalypt only) and tree. The trees are characterized by their species, age at sexual maturity, seed dispersal mechanism, germination probability, seedling survival probability and age.

\subsection{Cerrado Model Implementation}

The Cerrado discrete event simulation is written in SMPL1, a MATLAB (MathWorks 2010) implementation of SMPL (MacDougall 1987). SMPL1 was developed as a tool for life sciences students/researchers with some MATLAB experience, but otherwise little or no computer science background (Knadler 2011).

Each grid position is modeled as a possibly empty stack of trees and each tree on a stack is represented as a 2-component vector. The first component is the year the tree germinated or started growing out of an existing stump. The second component of a tree tuple is its species.

The basic simulation time unit is a year. Periodic simulation events occur yearly. 


\section{Knadler and Sinimbu}

\subsubsection{Eucalypt Population Initialization for the First Year}

The population of eucalypt trees in a plot, which regenerate from stumps, is generated prior to the start of the plot's simulation run. If it is an E. saligna plot, the number is 15 plus a uniformly distributed random integer in the interval $[0,60]$. While if it is an E. urophylla plot, the number is 25 plus a uniformly distributed random integer in the interval $[0,45]$. These distributions were chosen to represent the estimated number of stump-generated plants.

\subsubsection{Seed Dispersal Event}

Each of the current plot's grid positions are processed to determine if seeds of any of the 100 modeled species have landed on that position. If a seed has landed on the position, a corresponding tree is added to the position's stack of trees. The processing for this event consists of generating uniformly distributed pseudo random numbers in the range $[0,1]$ for each species. If the number is less than or equal to the species' probability of dispersing to that $4 \mathrm{~m}^{2}$ area, then a tree is created and pushed on the grid position's stack. After all species/grid position combinations are processed, this event schedules the seed germination event for the current time.

\subsubsection{Seed Germination Event}

This event pops all new trees off of each stack and using the species' probability of successful germination it determines if the seed germinates. If the seed germinates, then its tree is pushed back on the stack, else the tree is discarded. After every species/grid position combination is processed, this event schedules the seedling survival event for the current time.

\subsubsection{Seedling Survival Event}

This event pops all trees less than 3 years old off of each stack and based on the species' seedlings probability of survival determines if the tree survives. If it survives, then its tree is pushed back on the stack, else the tree is discarded.

\subsubsection{Plot Observation Event}

At the end of the current plot's simulation, each tree is popped off of its stack and if its age is sufficient for its species to meet the D30 3-centimeter diameter criterion, the species population is incremented. All trees are discarded and if there are additional plots to be modeled, the simulation processes the next plot. Otherwise the simulation writes the output files and terminates.

\subsubsection{E. urophylla Maturation Event}

The species seed dispersal probability is set to its parameter value. Prior to this event the probability was zero.

\subsubsection{E. saligna Maturation Event}

The species seed dispersal probability is set to its parameter value. Prior to this event the probability was zero. 


\section{Knadler and Sinimbu}

\subsubsection{Interval Data Generation Event}

The data output interval is a user specified number of years. At the end of each period, each tree is popped off its grid-position stack and if its age is sufficient for its species to meet the D30 3-centimeter diameter criterion, the species population is incremented for that interval. All trees are pushed back on their stack and the simulation continues. The matrices of interval data are saved at the end of the simulation for offline processing and graphics generation; e.g., see figures 6-9 later in the paper.

\subsection{Output Design}

The simulation output consists of summary data for end of each five-year interval and a spreadsheet with the same column formats used to analysis the tree census data. Thus the same data analysis programs may be used for the simulation results as for the census data.

\subsection{Simulation Validation}

Ecological simulations often present special validation challenges, because of the difficulty, cost, or time required to gather data for the systems being simulated. Typical of many ecological observation studies, this study did not have statistically significant sample sizes to use for model validation. Observation data were available for six E. urophylla plots and eight E. saligna plots. It is reasonable to estimate that data from approximately thirty randomly chosen plots would be required for statistically significant data (Crawley 2005).

The bootstrap method (Crawley 2005) provides a method for estimating the confidence intervals for collections of measurements by randomly sampling the measurement data with replacement. The confidence intervals, in figures 2-5, were determined by calculating the means of 10,000 samples of the observed data for sample sizes varying between 5 and 40 plots.

Validation consisted of comparing the means of two sample simulation runs for each of 10, 20, 30 and 40 simulated plots with the confidence intervals. With the exception of this validation analysis, all other simulation analysis in this paper is based on 40 plot sample sizes. This sample size was shown to be within the confidence intervals found with the bootstrap method. The simulation results and observations are both for 16 years post-harvest.

Using the same bootstrapping techniques, the simulation predicts a lower number of native species than the actual field observations. The $95 \%$ confidence interval for the mean number of native species in E. saligna plots is $[13.500,15.725]$ and the simulation results were a mean value of 9.000 with a minimum of 5 and a maximum of 17 species. In the case of E. urophylla, the $95 \%$ confidence interval for the mean number of native species is [10.525,14.525] while the simulation results have a mean value of 9.25 with a minimum of 4 and a maximum of 15 species. The only model parameter influencing the species distribution is the relative probability of a native species found on the censused Cerrado plots versus native species not found on the censused plots. Since the number of native trees is appropriate, no change was made to this parameter, as that would increase the number of simulated seeds that successfully germinated.

Given the concern about biodiversity, it was decided to accept a possible error of underestimating biodiversity versus an error of overestimating the number of native Cerrado trees that successfully recolonize the eucalypt plots. 


\section{eucalyptus}

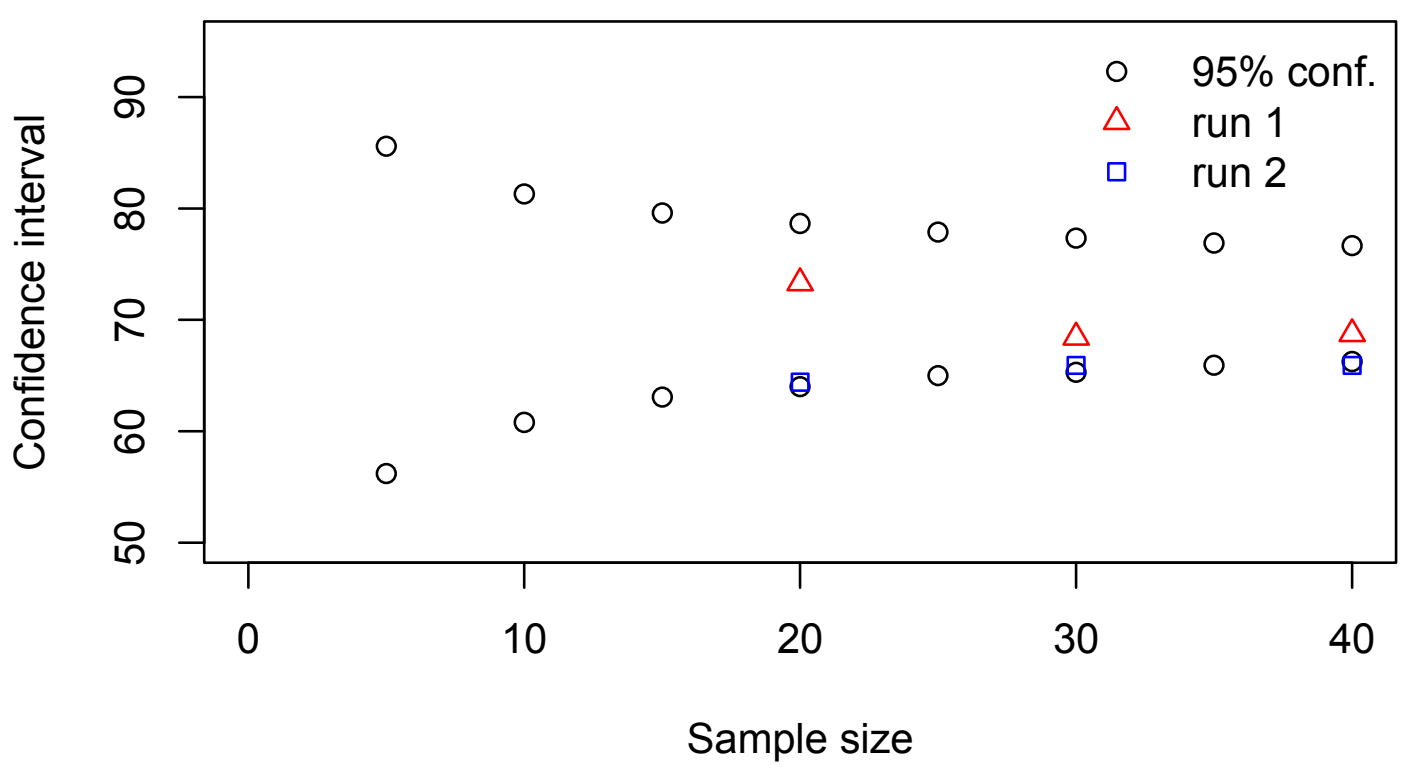

Figure 2: Predicted mean number of eucalypt trees on abandoned E. urophylla plots

\section{native cerrado}

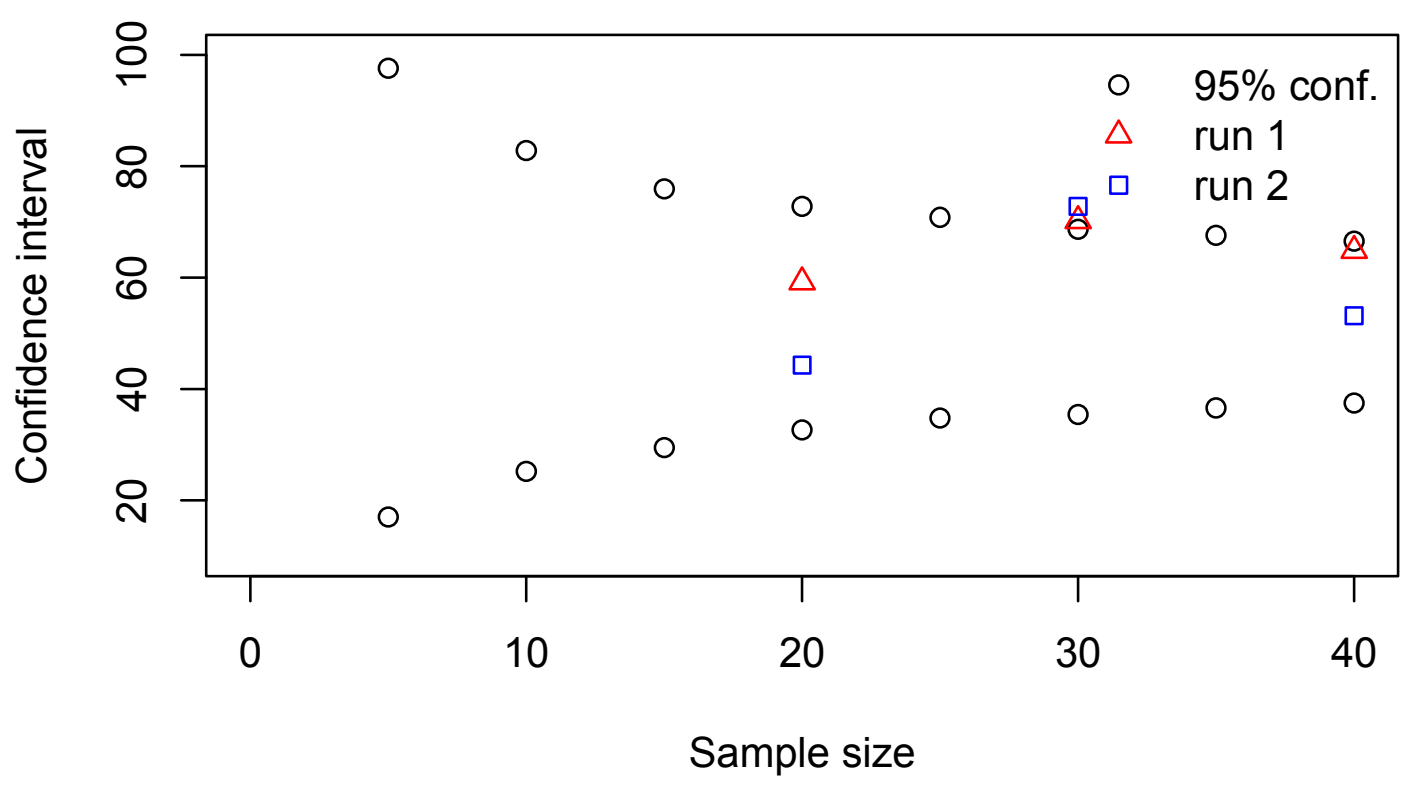

Figure 3: Predicted mean number of native Cerrado trees on abandoned E. urophylla plots 


\section{eucalyptus}

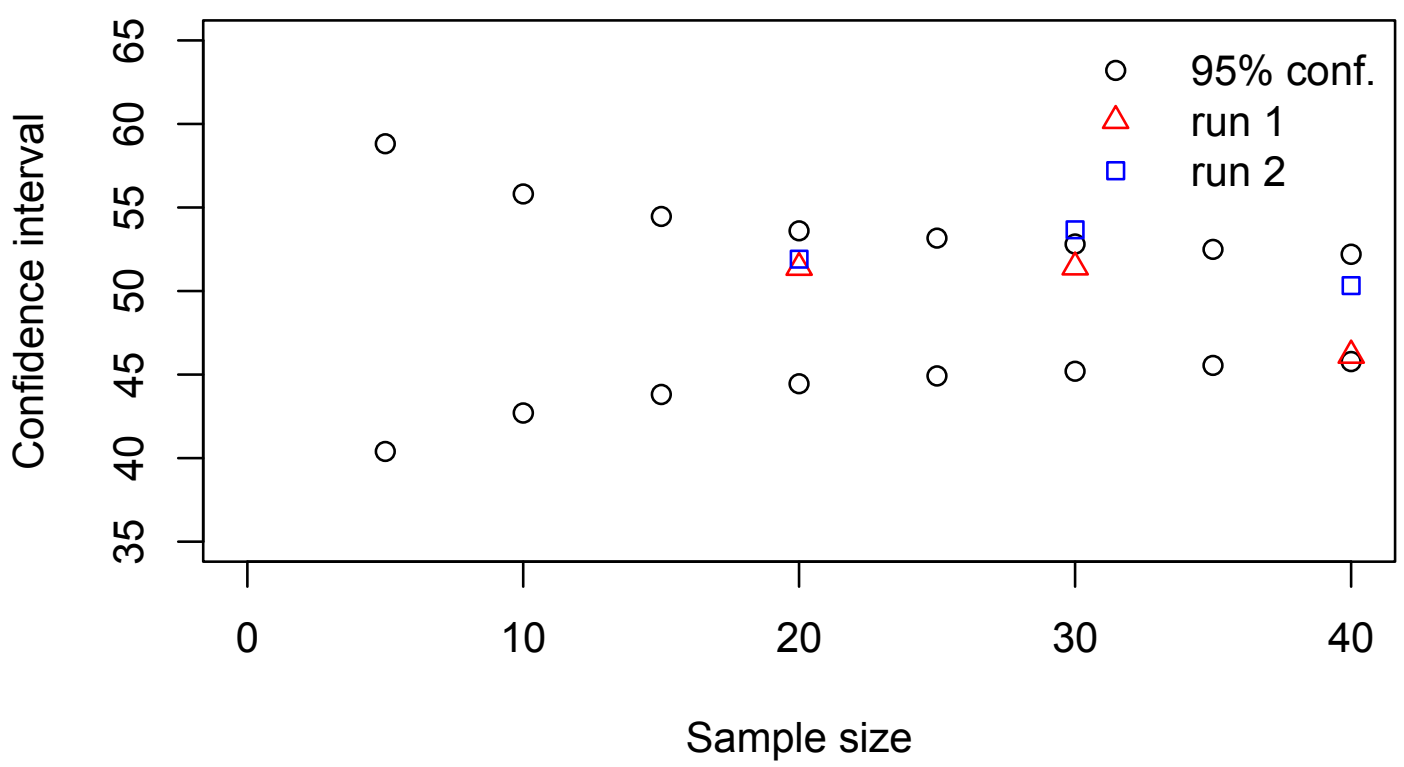

Figure 4: Predicted mean number of eucalypt trees on abandoned E. saligna plots

\section{native cerrado}

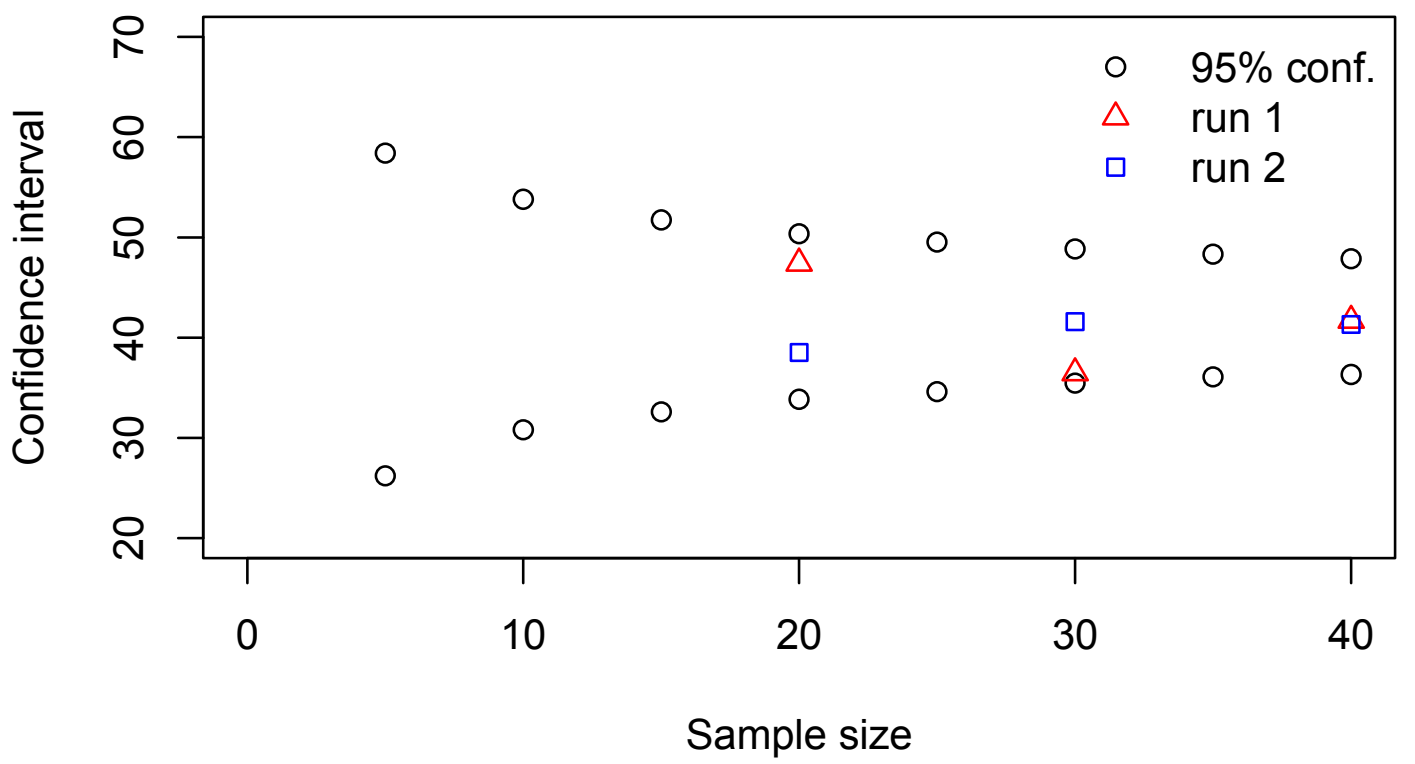

Figure 5: Predicted mean number of native Cerrado trees on abandoned E. saligna plots 


\section{Knadler and Sinimbu}

\section{SUMMARY AND CONCLUSIONS}

The model results present a positive outlook for the abandoned plantations in the context of Couto and Betters' (1995) environmental impact analysis. Couto and Betters' (1995) analysis suggests that concern about the impact of the eucalypts on Cerrado flora, fauna and water supply might be misplaced.

As calculated from the data in Table 3 , an average hectare $\left(10,000 \mathrm{~m}^{2}\right)$ of abandoned plantation is predicted to have either 400 or 540 recolonized native trees for a E. saligna or E. urophylla plantation land respectively. On average, E. saligna plots had 12.5 different native Cerrado species and E. urophylla plots had 9.1 different native Cerrado species. Thus the botanical biodiversity predicted for the abandoned plantations is less than for the native areas. The native Cerrado plots had a minimum of 12 species, a mean of 20.8 species, and a maximum of 27 species with a standard deviation of 5.09 species. But the recolonized plantations do considerably improve their biodiversity compared to their previous state under silviculture.

Table 3: Number of individual trees predicted per abandoned eucalypt plantation $1000 \mathrm{~m}^{2}$ plot 50 years post-harvest.

\begin{tabular}{|c|c|c|c|c|c|c|}
\hline & \multicolumn{3}{|c|}{ Native Cerrado Species } & \multicolumn{3}{c|}{ Eucalypts } \\
\hline & Minimum & Mean & Maximum & Minimum & Mean & Maximum \\
\hline E. saligna plots & 5 & 40 & 99 & 19 & 57 & 99 \\
\hline E. urophylla plots & 4 & 54 & 163 & 58 & 108 & 106 \\
\hline
\end{tabular}

Figures 6-9 show the predicted populations at five-year intervals. Note that the eucalypt population is exhibiting linear growth. This growth will continue until it is limited by one of two factors, neither of which is modeled. First, as seen in the native Australian forests there is a maximum sustainable tree density, although there are countless seeds dispersed in the eucalypt forests, logistic effects result in a stable population. Second, we have not modeled the spread of native grasses. Field observations have shown that when these grasses are fully established they inhibit the successful germination of the eucalypts. Without unavailable field data, we cannot project what the maximum mature eucalypt population will be. It is reasonable to assume that it will be at most what is achieved with silviculture. Couto and Betters (1995) give that density as one tree per either 6 or $9 \mathrm{~m}^{2}$ implying an upper limit, under optimal conditions, of 167 eucalypts per plot.

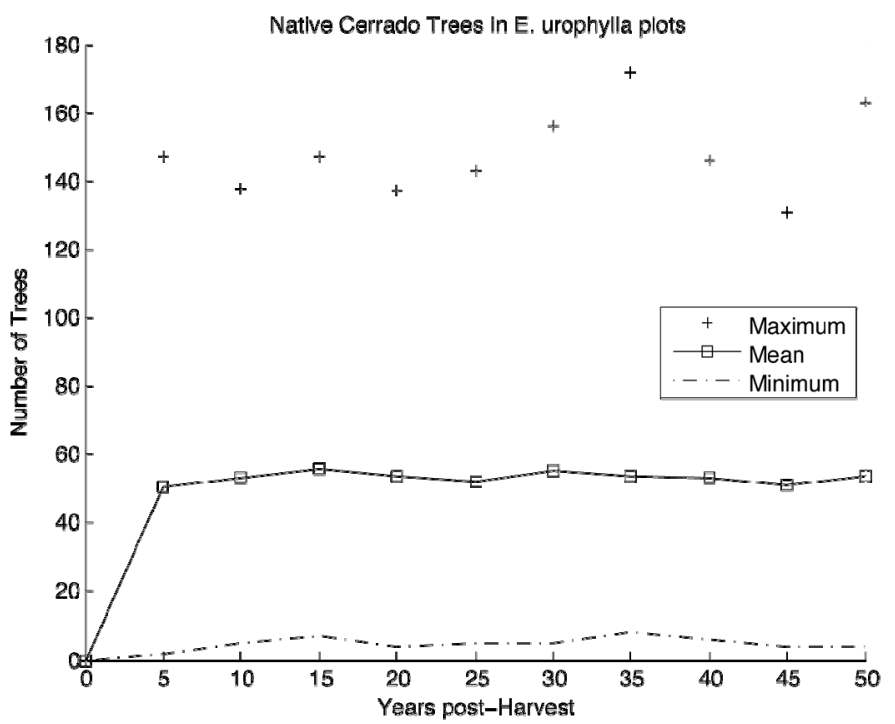

Figure 6: Native Cerrado tree population in E. urophylla plots 


\section{Knadler and Sinimbu}

The presence of eucalypts in the Cerrado is a significant departure from the pristine state. The eucalypts are taller (up to $65 \mathrm{~m}$ ) than the native Cerrado species $(5-7 \mathrm{~m}$ ) and this will result in entirely different aesthetics and possibly microclimate. Couto and Betters (1995) analysis is based partially on comparison with other forests rather than comparisons to the Cerrado. Their analysis suggests that there is little or no negative environmental impact compared to tall pine or oak forests, but tall growth forests are not a good representation of Cerrado. The tall trees require more water than the Cerrado "scrub" trees, which are adapted to dryer environments.

Both E. saligna and E. urophylla are suited to the Brasilia National Forest climate including its mean annual rainfall and its mean dry season length. This suggests that the eucalypts will have normal mortality and reproduction. Individual trees will survive longer than observed in other 50 year-old E. saligna plantations (Couto and Betters 1995) and the species will flourish.

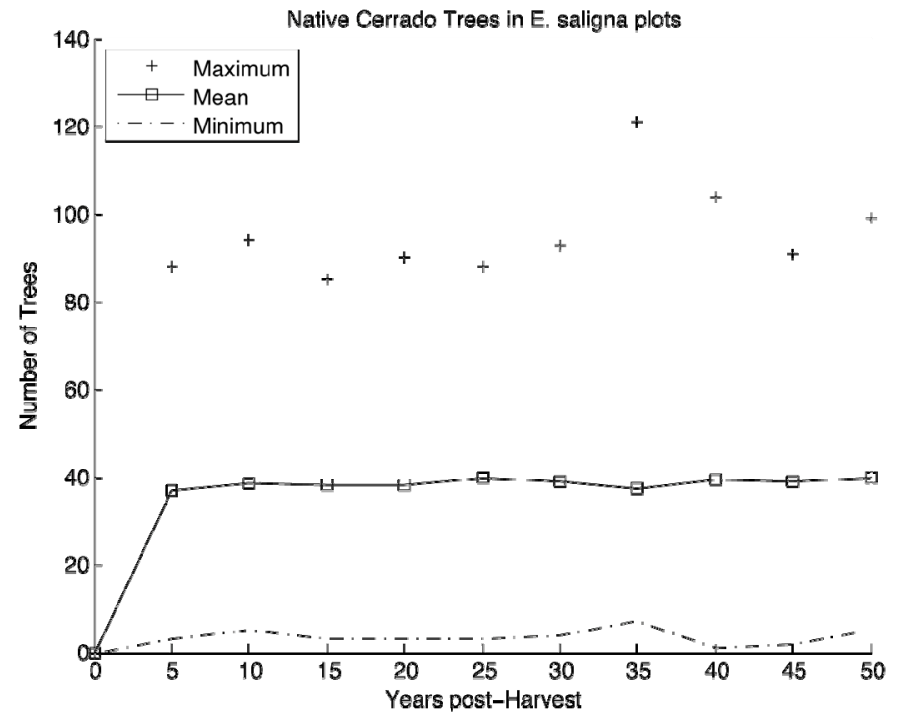

Figure 7: Native Cerrado tree population in E. saligna plots

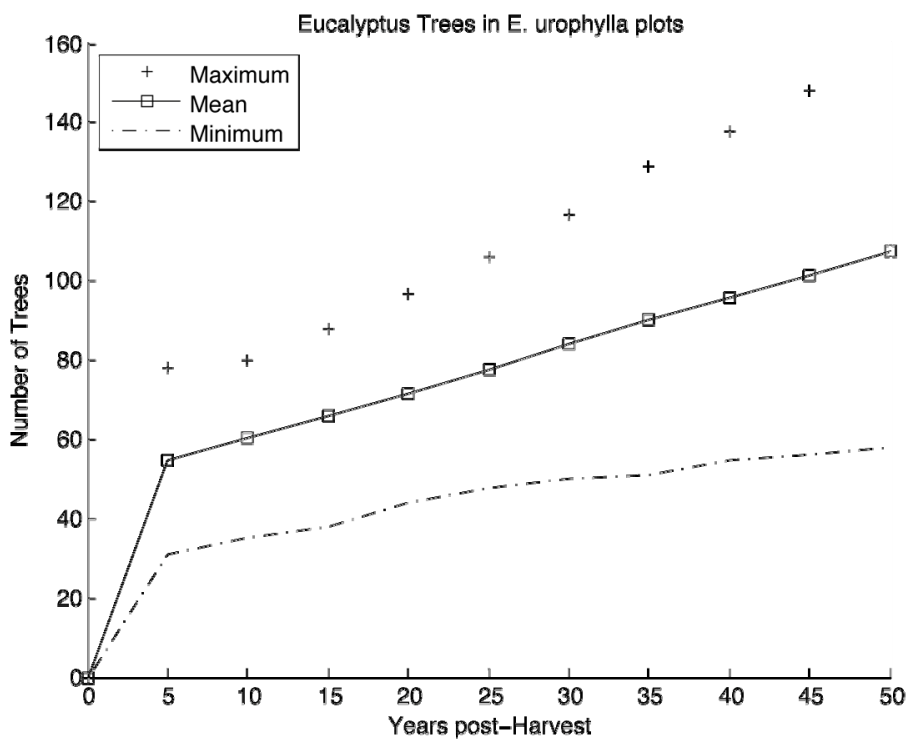

Figure 8: Eucalypt population in E. urophylla plots 


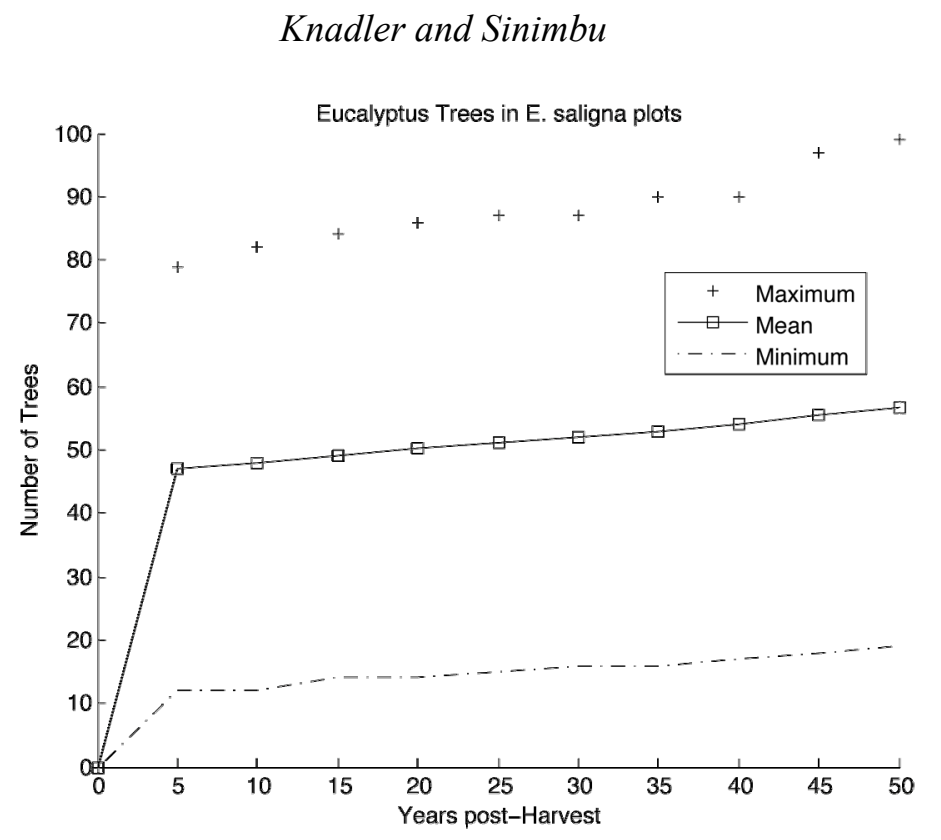

Figure 9: Eucalypt population in E.saligna plots

\section{ACKNOWLEDGMENTS}

We acknowledge logistical support from the Brasilia National Forest during field data collection, and the Water, Environment, Science, Teaching Fellowship for funding support for Georgia Sinimbu.

\section{REFERENCES}

Alternativas. 2001. "O uso múlitplo das florestas renováveis.” Ambietec On-line [S1] 2. Accessed July 23, 2011. http://www.ecolatina.com.br/ambitec/ed03/index.html.

Crawley, M. J. 2005. Statistics, An Introduction using R. Chichester, England: John Wiley and Sons, Ltd.

Couto, L. and D. R. Betters 1995. "Short-Rotation Eucalypt Plantations in Brazil: Social and Environmental Issues." ORNL/TM-12846. Oak Ridge National Laboratory, Oak Ridge, Tennessee

Lang, C. 2011. "Brazil: Women impacted by eucalyptus plantations speak out.” Accessed March 15. http://pulpinc.wordpress.com/2009/03/13/brazil-women-impacted-by-eucalyptus-plantations-speakout/.

Law, A. M., and L. D. Kelton. 1991. Simulation Modeling and Analysis, Second Edition. New York, New York: McGraw-Hill,.

Knadler, C. E. 2011. SMPL1, A MATLAB SMPL Simulation System, User's Guide. Available on email request.

Lazowska, E. D., J. Zahorjan, G. S. Graham, and K. C. Sevcik. 1984. Quantitative System Performance: Computer System Analysis Using Queueing Network Models. Englewood Cliffs, New Jersey: Prentice Hall.

MacDougall, M. H. 1987. Simulating Computer Systems: Techniques and Tools. Cambridge, Massachusetts: The MIT Press.

MathWorks 2011. Programming Fundamentals. Accessed March 5. http://www.mathworks.com/help/techdoc/matlab_prog.

Myers, N. 1988. “Threatened Biotas: 'Hot spots' in Tropical Forests.” The Environmentalist 8: 187-208.

Myers, N., R. A. Mittermeier, C. G. Mittermeier, G. A. B. da Fonseca and J. Kent. 2000. "Biodiversity Hotspots for Conservation Priorities." Nature 403: 853-858. 


\section{Knadler and Sinimbu}

Neilson, D. 2000. "The Global Eucalyptus Resource and Some Solid Wood-Panel Product Development Issues." In IUFRO Conference on the Future of Eucalypts for Wood Products. Launceston, Australia.

Sinimbu, G. 2006. "Regeneração da flora native do Cerrado em plantios de Eucalyptus spp. na Floresta Nacional de Brasília-DF." Undergraduate monography, Brasília, DF: Departament of Forestry Engineering, University of Brasilia.

Stape, J. L. 2002. "Production Ecology of Clonal Eucalyptus Plantations in Northeastern Brazil." Ph.D. Dissertation. Colorado State University, Fort Collins, Colorado.

World Agroforestry Centre. 2011a. "AgroForestry Tree Database, Eucalyptus saligna." Accessed March 11.

http://www.worldagroforestrycentre.org/sea/Products/AFDbases/AF/asp/SpeciesInfo.asp?SpID=812.

World Agroforestry Centre. 2011b. "AgroForestry Tree Database, Eucalyptus urophylla." Accessed March 11.

http://www.worldagroforestrycentre.org/sea/Products/AFDbases/AF/asp/SpeciesInfo.asp?SpID=821.

\section{AUTHOR BIOGRAPHIES}

CHARLES E. KNADLER, JR. is a consultant and researcher. He was formerly a senior engineer and senior manager for IBM, an executive in AOL's Member Services Division and Associate Professorial Lecturer in Engineering at The George Washington University. He received his B.E.S. degree in mechanics from The Johns Hopkins University and his M.S. and D.Sc. degrees in computer science from The George Washington University. His research interests include mathematical biology, development and deployment of large-scale software systems, and naïve agent support systems. He is a member of ACM, IEEE, and SIAM. His email address is knadlerc@aol.com.

GEORGIA SINIMBU is a Ph.D. student in the Department of Biology, University of Utah. She received a Bachelors of Forestry Engineering from the University of Brasília, Brasília, Brazil and a Master Degree in Biology (Ecology) from the National Institute for Amazonian Research, Manaus, Brazil. The census data used in the simulations in this paper are the results from her Bachelor's dissertation. Her research interest is plant-animal interactions in tropical forests. Her email address is g.sinimbu@utah.edu. 